\title{
"Our Doors Are Open to Everybody": Public Libraries as Common Ground for Public Health
}

\author{
Anna Uma Morgan • Roxanne Dupuis • \\ Eliza Davenport Whiteman • Bernadette D'Alonzo • \\ Carolyn C. Cannuscio
}

Published online: 9 January 2017

(C) The New York Academy of Medicine 2017 both an asset and a challenge - and they saw a role for the library in fostering intergroup relationships and understanding. This finding was particularly compelling because of its relevance across the USA, where there are over 9000 public libraries, which host over 1.5 billion visits annually [7]. Public libraries are free and open to all, and are seen by nine out of ten Americans as valuable to community life [8]. This shared view is remarkable at this moment of deep cultural and political strife.

Many of our interviews were conducted in South Philadelphia, the site of a new Community Health and Literacy Center that combines a ground floor public library, adult and pediatric health clinics, and a recreation center. With over $20 \%$ of residents reporting being foreign born, South Philadelphia is one of the city's most diverse neighborhoods [9]. Many neighborhood residents spoke of a desire for increased intercultural exchange, improved access to English as a Second Language (ESL) courses, and sustained support for refugees and immigrant families. They saw the public library as a logical site for all of these activities. One community resident discussed the need to strengthen "ethnic relations," and "bring all the cultures together to sit down to talk, maybe hash out stereotypes or perceived stereotypes that they have about each other and just flatten it out so we can all have a better understanding of who we are" (Fig. 1).

Many of the residents emphasized the need for additional opportunities for children and youth, who they feared were not well served by existing schools and programs - leading many young people to engage in unsafe or illegal activities. These concerns were 


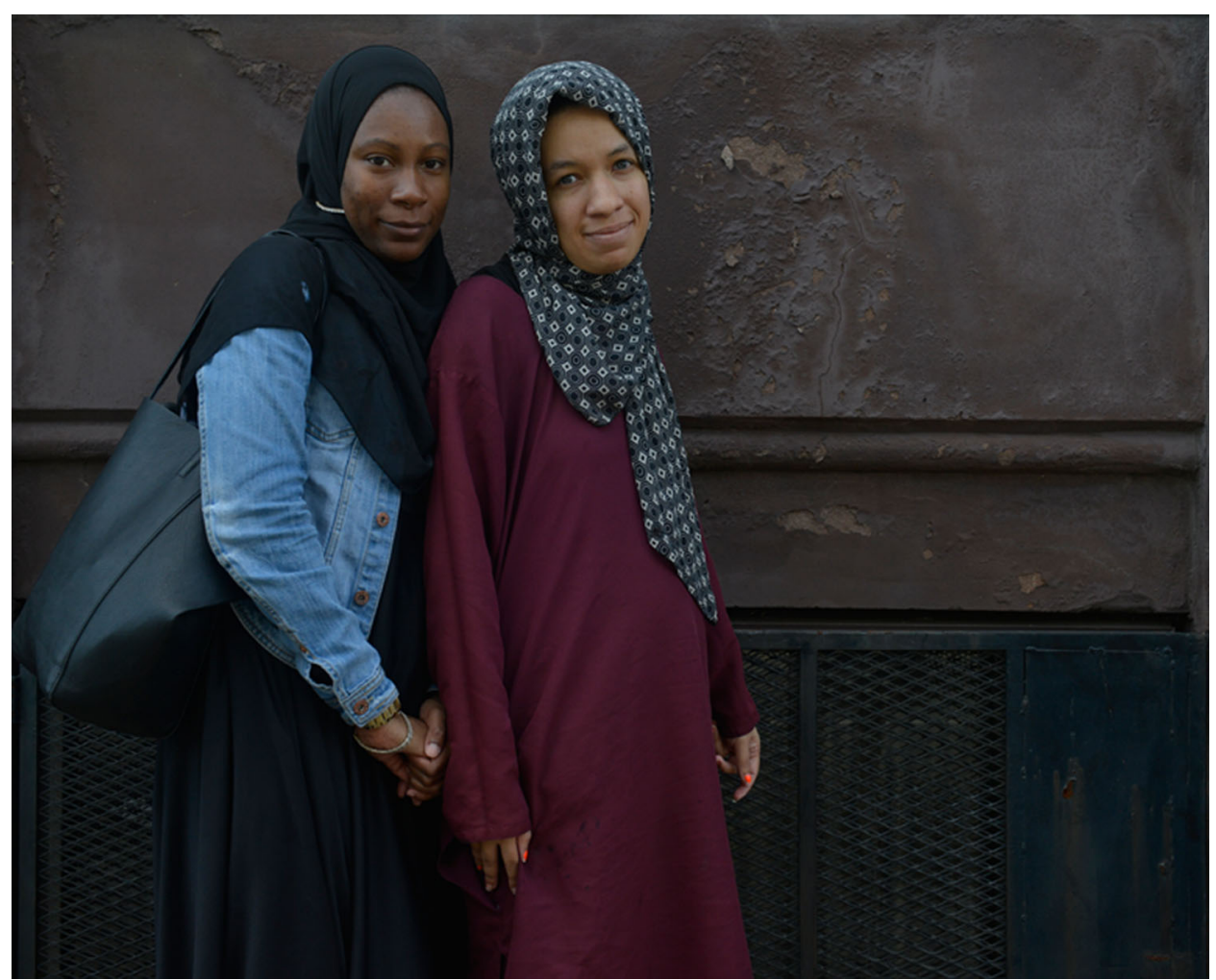

Fig. 1 Philadelphia is among the poorest and most segregated big cities in the country [2]. Recognizing these community divisions, residents of South Philadelphia expressed a desire for programming to encourage individuals from different groups to meet in a neutral space and engage with one another, with the goal of improving intercultural communication and relationships. Photograph credit to Nema Etebar

main branch of the library. The current program (Fig. 2) includes participants who have just arrived in the USA from Afghanistan, Bhutan, Congo, Iraq, Malaysia, Pakistan, Syria, and Uganda. Through shared meals and conversation, the participants are introduced to the library system, the basics of American foodways, and, perhaps most importantly, one another.

Through its 61 locations, the Free Library of Philadelphia hosts nearly 6 million visits annually, in a city of 1.5 million people [10]. In addition to offering access to books and electronic resources, the library actively addresses the social determinants of health, offering educational, social, and cultural programming that engages more than 500,000 diverse Philadelphians annually. And library staff members are committed to answering the call for strengthening the community and its health [11]. Public libraries are particularly well-suited to this task, offering a vital common ground, and a place for cross-cultural and intergenerational dialogue - and offering hope for greater integration and tolerance in our "highly sorted" city. 


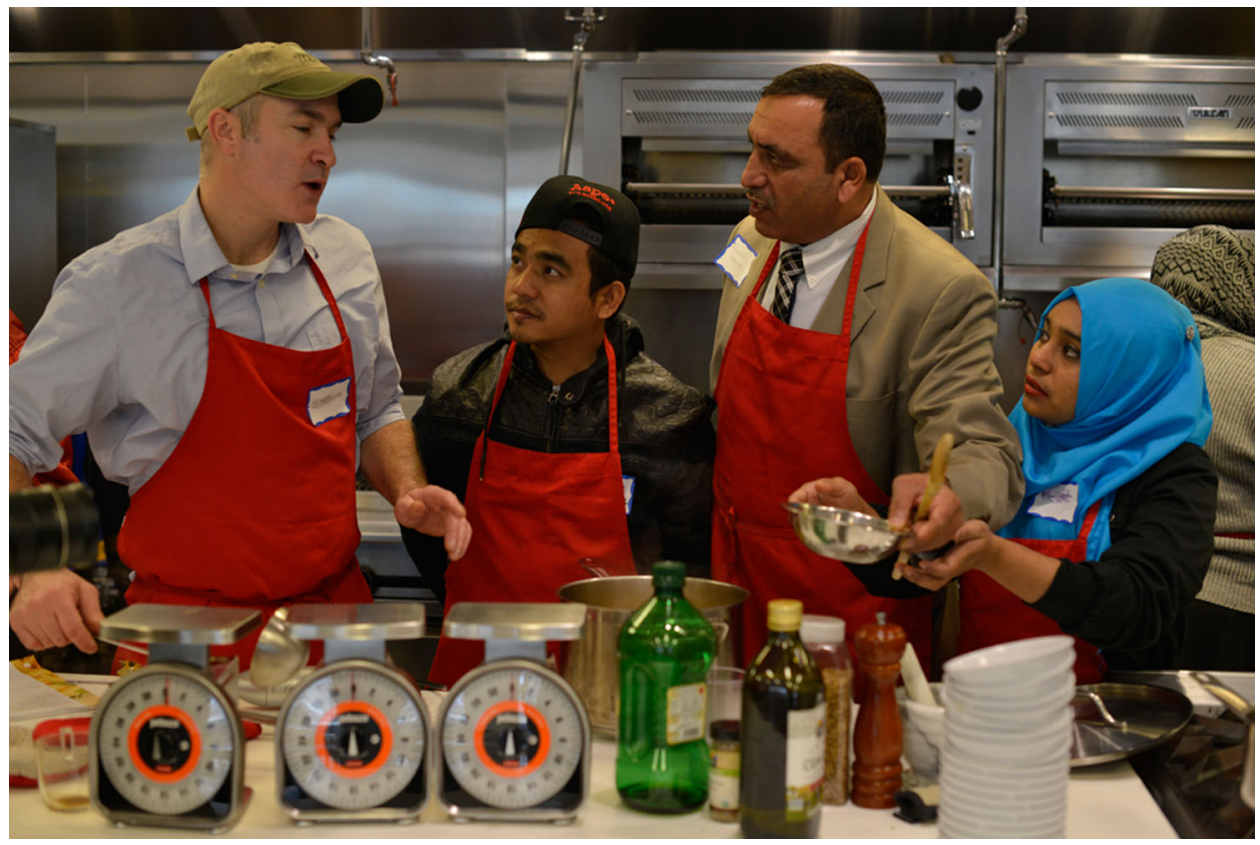

Fig. 2 At the Free Library of Philadelphia, the Culinary Literacy Center welcomes refugees from many nations to join the Edible Alphabet class, an ESL and life skills program. Here, the lead chef teaches students how to make pasta primavera. For many of the

Acknowledgements We the authors thank the CDC-funded Prevention Research Center and the Penn Center for Public Health Initiatives for their financial and practical support of this work. We also thank photographer Nema Etebar and interviewers Amy Graves and Kiahana Brooks, as well as the study participants. This work was made possible by our colleagues at the Free Library of Philadelphia. This work was approved by the University of Pennsylvania Institutional Review Board.

\section{References}

1. Fullilove MT. Urban Alchemy: restoring Joy in America's Sorted-Out Cities. 1st ed. New York, NY: New Village Press; 2013.

2. Silver N. The most diverse cities are often the most segregated. FiveThirtyEight. May 1, 2015. http:/fivethirtyeight. $\mathrm{com} /$ features/the-most-diverse-cities-are-often-the-mostsegregated/. Accessed April 18, 2016

3. Cannuscio CC, Tappe K, Hillier A, Buttenheim A, Karpyn A, Glanz K. Urban food environments and residents' shopping behaviors. Am J Prev Med. 2013; 45(5): 606-614. students, this class is a first introduction to the USA, with some students joining the class as soon as 2 weeks after arriving in the USA. Photograph credit to Nema Etebar

4. Williams DR, Collins C. Racial residential segregation: a fundamental cause of racial disparities in health. Public Health Rep. 2001; 116(5): 404-416.

5. Moody J. Race, school integration, and friendship segregation in American. Am J Sociol. 2001; 107(3): 679-716.

6. Vallas SP. Rediscovering the color line within work organizations - the 'knitting of racial groups' revisited. Work Occupations. 2003; 30(4): 379-400.

7. Institute of Museum and Library Services. Public Libraries in the United States Survey: Fiscal Year 2013. Washington, DC: Institute of Museum and Library Services; 2016.

8. Zickuhr K, Rainie L, Purcell K, Duggan M. How Americans value public libraries in their communities. Washington, DC: Pew Research Center; 2013.

9. The Pew Charitable Trusts. Philadelphia 2015: The State of the City. http://www.pewtrusts.org/en/research-andanalysis/reports/2015/03/philadelphia-2015-the-state-ofthe-city. Published March 28, 2015. Accessed April 18, 2016.

10. Free Library of Philadelphia. Free Library of Big Ideas: 2015 Annual Report. Philadelphia, PA2015.

11. Morgan A, Dupuis R, D'Alonzo B, et al. Beyond books: public libraries as partners for population health. Health Aff. 2016; 35(11): 2030-2036. 